\title{
Some Aspects Conditioning the Achieving of Filaments for 3D Printing from Physical Modified Corn Starch
}

\author{
DOINA DIMONIE ${ }^{1,2 *}$, CELINA DAMIAN², ROXANA TRUSCA2, MARIA RAPA ${ }^{3}$ \\ ${ }^{1}$ National Institute of Research \& Development in Chemistry and Petrochemistry- ICECHIM, 202 Splaiul Independentei, 60208, \\ Bucharest, Romania \\ ${ }^{2}$ Politehnica University of Bucharest, Faculty of Applied Chemistry and Material Science,1-7 Polizu Str., 011061, Bucharest, \\ Romania \\ ${ }^{3}$ ICPAO Medias, 8 Carpati Str., 551022, Medias, Romania
}

\begin{abstract}
It was found that the obtaining of quality 3D printing filaments, without defects and natural color, from corn starch physical modified with PVOH, depends also on the melting behavior at compounding, both of starch and of $\mathrm{PVOH}$, and on the controlling of the process sensitivity of the new compounds. A comparable melting behavior was possible by compounding the two polymers as powders with similar small sized particle. The controlling of the process sensitivity was achievable, mainly, by diminishing the melt resistance to flow, via formulation with a flow agent. The selected compounds which had controlled miscibility, few defects and natural color were shaped, with good results, as filaments with silky and smooth surface. These filaments were compatible with $3 \mathrm{D}$ printing because proved to have the ovality and the diameter tolerance in the accepted limits in the fields.
\end{abstract}

Keywords: Compounds, thermoplastic starch, 3D printing, miscibility, process sensitivity, melt degradation

After previous two industrial revolution from the past centuries, a mechanical one and energetic other, it is believed that, the next future revolution will be a digital one, possible the 3D printing, techniques which is gaining more and more ground, even in manufacturing items for heavy-duty areas [1]. The application of the 3D printing (additive/cumulative) procedure as compared with the substractive those, allows the achieving, in fast manufacturing processes, several, robust and compact items, sometimes even with layered structure, better adapted to the market requirements.

One of the used 3D printing techniques is the deposition of melted filaments (FDM) [2, 3]. These filaments are obtained from synthetic and/or renewable polymeric compounds [2-4] and must meet the characteristics required both by the $3 \mathrm{D}$ printing for doing printing in good conditions and by the desired application in order to make items with needed functional properties. A good 3D filament must have diameter of $1.75 \mathrm{~mm}$ or $2.85 \mathrm{~mm}$ (tolerance not greater than $+/-0.05 \mathrm{~mm}$ or even $+/-0.02 \mathrm{~mm}$ ) and ovality (the difference between two perpendicular diameters) not exceeding $0.06 \mathrm{~mm}$ [3]. The polymeric filaments are discarded as inappropriate for 3D printing if they cause the clogging of the printer's nozzle (which has diameter not greater than $0.4 \mathrm{~mm}$ ) or /and the deposited layers (with thickness between $0.07 \mathrm{~mm}-0.3 \mathrm{~mm}$ ) do not adhere well to each other because of the irregular flow of the melt during printing. The natural colored filaments are elminated also when they are beige or even yellow-brown colored.

Starch has yet great potential to be used in polymer technology, as notable alternative of petrochemical plastics[5-8]. It is widely known as repeating glucose monomers, consisting of linear amylose and highly branched amylopectin. A new customized application for starch based-compounds is the 3D printing - FDM method. The obtaining of $3 \mathrm{D}$ printing filaments is not a simple task since even the achieving of thermoplastic compounds based on starch, via melt processing, is not an easy one.
For usage as thermoplastic compounds with functional properties suitable for various applications, starch was melt compounded with synthetic (both hydrophobic, nondegradable - polyolefin, polystyrene, polyvinyl chloride etc. or/and hydrophilic-, degradable - polyvinyl alcohol (PVOH), polyesters, etc.) or/and renewable polymers (cellulose, natural rubber, polylactic polymers, poly (hydroxybutirate) etc.) $[9,10]$.

Several known studies regarding the starch - PVOH compounds [11-35] refer to issues as: acquiring methods [11, 12], plasticizer types [15-22], parameters influencing functional properties $[10,11,13,14]$, other polymeric modifiers [23, 24], nano-composites [25], compatibility $[26,28]$, cross-linking [26, 27], starch phase transition [2934]. However, about the possibilities to control both the defects and the undesired color change of starch based materials at melt compounding, only general data, in the best case, are known [35]. Also, few knowledges can be found about the usage of starch based-compounds as 3D printing filaments, most of them only as commercial informations [36].

During compounding of white powder of starch with white powder of PVOH or during flowing of their compounds in an elongational extruder (indexer), nonconformities as changing of color from natural into shades of beige, yellow, brown or defects as cracks, fractures or voids, have been observed. Compounds with such nonconformities cannot be accepted in any circumstances, more in case of 3D printing.

Obviously, considering the already known high degradability of starch $[7,15]$ and of $\mathrm{PVOH}[36-40]$, the color change was linked with the degradation during melt compounding. Breaking or/and crosslinking of macromolecules with molecular weight diminishing and double bonds formation responsable for the coloring of the starch based-compounds, is the result of the first stage of mechano-thermo-oxidation during melt compounding $[14,15]$. Protection against degradation, via stabilization

\footnotetext{
* email: ddimonie@yahoo.com
} 
[41-45] at melt processing [41, 43-45] and/or for usage [42], as counter-methods, in technological practice is used. However, it was observed that, the formulation of the starch-PVOH compounds with melt processing antioxidants does not remove the undesirable coloring at compounding. The developed defects as voids, cracks and fracture, most likely, have other origins.

The paper presents the possibility to engineer the turning of corn starch through modification with PVOH into thermoplastic compounds with few defects and natural color, which can be shaped as quality filaments with silky and smooth surface, compatible with 3D printing.

\section{Experimental part}

Methods and materials

For avoiding the development of defects (cracks, voids, fractures, etc.) and the coloring of the starch-PVOH compounds at their achieving, later at shaping as filaments and at 3D printing, a method based on monitoring both the melting behavior of the two polymers and the controlling the process sensitivity of each compound, has been conceived. In this context the following experimental paths were investigated:

-The melting behavior of starch and PVOH powder;

-Controlling the process sensitivity of each compounds via:

-The influence of the stabilization -plasticization level;

- Finding the windows of meltcompounding conditions;

- Diminishing the melt internal friction.

To achieve softcompounds compatible with $3 D$ printing for various, multifunctional, applications, the formulations have been so designed to control the glass transition values. Starch-PVOH compounds with 0/100-100/0 blending ratio and following additives related to 100 parts blend of starch with PVOH: (5-60 parts) plasticizers, ( $0-5$ parts) stabilizers, (0-2 parts) flow agent were made. For each composition, the two polymers and additives were first pre-blended in solid state, according to the dry-blending technique. The compounding was made in a Brabender plastograph, in composition-dependent conditions $\left(110-170^{\circ} \mathrm{C}\right.$ temperature, 5-10 min compounding time, 75 rpm-100 rot/min rotors speed). After meltcompounding, each blend was rolled into sheets, on a laboratory roller, under chosen conditions $\left(125-160^{\circ} \mathrm{C}\right.$ temperature and $24 \mathrm{rpm} / 28 \mathrm{rpm}-$ rolls speed). Selected formulations were compounded granulated on a double screw extruder $\left(150-175^{\circ} \mathrm{C}, 25\right.$ rpm) and then, were shaped on a Gottfert rheometer $\left(95^{\circ} \mathrm{C}\right.$ $125^{\circ} \mathrm{C}$ ) as bands to measure the surface roughness. The second selection was made according to the roughness of the extruded bands. The compounds which had an optimal roughness were shaped than as 3D filaments with 1.75 $\mathrm{mm}$ diameter, on a Gottfert rheometer $\left(95-125^{\circ} \mathrm{C}, 35 \mathrm{rpm}\right)$ equipped with a laboratory line for calibration, cooling, pulling, rolling of the resulted filaments. The samples for mechanical characterization have been obtained through injection (Ray-Ran injection device) in selected conditions (90-170 ${ }^{\circ} \mathrm{C}$, 5min.-10min.-10min., 200 barr). Because the starch-PVOH compounds with less then $50 \%$ starch are more susceptible at temperature changes [14], only the influence of the injection temperature on the mechanical properties was studied. The 3D printing has been done on a 3D printer-model UP Plus 2.

In order to identify the influence of the two polymers particles size on the melting behavior and on the compounds defects, both unsieved polymers as well as, sieved fractions separated from the two polymers (P1 starch and P2 - PVOH) were 1/1 compounded, in the same formulation and conditions.
The new compounds were characterized with the following methods and equipment:

a. Particle size analyses of polymer powder - shaking sieve HAVER- Test Sieve Shaker EML 200, working at amplitude of $1.0 \mathrm{~mm}, 15 \mathrm{~min}$ and $60 \mathrm{~s}$.

b. Compounds morphology:

-X-Ray diffraction (XRD) - diffractometer Panalytical XPERT MPD type with Bragg- Brentano geometry.

Scanning electron microscopy (SEM) - scanning electron microscope Quanta INSPECT F equipped with electron field emission gun - EFG with a resolution of 1.2 $\mathrm{nm}$ was used. Lyophilisation was performed in a CHRIST ALPHA 1-2 LD plus freezer in the following conditions: main drying at - 42.9 and 0.091 mbar and finally drying at $43.2^{\circ} \mathrm{C}$ and 0.012 mbar.

c. Rheological properties of the melts - the melt flow index method [46, 47]. The measurements were performed on a 4000 DYNISCO indexer - LMI type, which had provided the following properties: shear rate (Sh R), melt flow index (MFI), dynamic viscosity (DV), and melt density. The activation energy of viscous flow $\left(E_{a}\right)$ was calculated according to $[46,47]$. Working conditions: nozzle of 2.09 ratio between height and diameter (h/D), in the temperature range from 145 to $175^{\circ} \mathrm{C}$, at three loading levels: low $(2.16 \mathrm{~kg}$ and $3.8 \mathrm{~kg})$, medium $(5 \mathrm{~kg})$ and high $(10 \mathrm{~kg})$ and cutting time of $30 \mathrm{~s}$.

d. Degradation by color change: Yellow index was measured with leucometer, Carl Zeiss 2781135/1 Jena.

e. Mechanical tests - Universal Testing Machine Instron 3382 with $100 \mathrm{kN}$ load-cell at room temperature, with previous temperature and humidity conditioning for $48 \mathrm{~h}$. The specimens 5A type according to ISO 527, were tested for each sample and analyzed using the Bluehill Software with a rate of $5 \mathrm{~mm} / \mathrm{min}$ until fragmentation occurred. The experiments were performed on parallel specimens to ensure consistency. Measurements were done 5 times for each sample and the average value was reported.

f. Dynamic mechanical analysis (DMA)- TRITEC $2000 \mathrm{~B}$ (Triton Technologies) in a single cantilever mode, from -60 to $100^{\circ} \mathrm{C}$ with $1 \mathrm{~Hz}$ frequency and $5^{\circ} \mathrm{C} / \mathrm{min}$. heating rate.

g. Roughness of the extruded bands -Portable digital roughness TR 200 type - Phynix

$\mathrm{h}$. The filament diameter tolerance: measurement of the diameter at every $0.5 \mathrm{~m}$ for $300 \mathrm{~m}$ filament length.

i. Ovality of the filaments -SEM micrographs.

The following materials, thermo-stable in the compounding-shaping as filaments-3D printing sequence, were used:

-Corn starch (Pilot synthesized) with 70\% amylopectin, glass transition at $80^{\circ} \mathrm{C}$ and melting at $180^{\circ} \mathrm{C}$. Up to $210^{\circ} \mathrm{C}$ it loses $10.63 \%$ weight, and between 200 and $400^{\circ} \mathrm{C}$ it loses 73.35\%;

-Polyvinyl alcohol (Pilot synthesized, filme degree) with $84 \%$ degree of hydrolysis (HD), $T$ of $60^{\circ} \mathrm{C}$ and melting at $150^{\circ} \mathrm{C}$. Mass loss up to $120^{\circ} \mathrm{C}$ approx. 3.01 and $81.43 \%$ between 170 and $400^{\circ} \mathrm{C}$;

-Plasticizers: Glycerine (ReAgent Chemical Services Ltd., GLYC-2593-06), urea (SABIC, also as micro-organism nitrogen source, technical grade);

-Stabilizers: $3 / 1$ sterically hindered phenol and sterically hindered phosphite (Innua Petrochem, Irganox B 215);

-Flow agent: metalic stearates (calcium stearatetechnical grade, Parchem CAS1592-23-0).

\section{Results and discussions}

The melting behaviour of starch and PVOH powder

The particles of each of the two pilot obtained polymers, respectively the corn starch and PVOH particles, had own size distribution and shape. The corn starch has rectangular 
particles, smaller than $100 \mu \mathrm{m}$ in proportion of $94 \%$ ( 100 $80 \mu \mathrm{m} / 22 \%, 80-63 \mu \mathrm{m} / 18 \% ; 63-40 \mu \mathrm{m} / 28 \% ; 40-20 \mu \mathrm{m} /$ $5 \%)$. The PVOH has spherical particles [48] with larger diameter than $100 \mu \mathrm{m}$, in proportion of $90 \%$ ( $100-80 \mu \mathrm{m} /$ 32\%; $200-100 \mu \mathrm{m} / 27 \%$; $300-200 \mu \mathrm{m} / 30 \%)$.

Since the particles of the two polymers were compounded as such, without sieving, all the acquired compounds had defects as cracks, voids, fractures etc. and were, more or less colored, in beige or even brown. The XRD diffractograms of the 1:1 starch-PVOH compounds achieved using the same formulation and identical compounding conditions but different sieved fractions have almost comparable shape, totally different from those of starch and PVOH [49] (fig. 1).

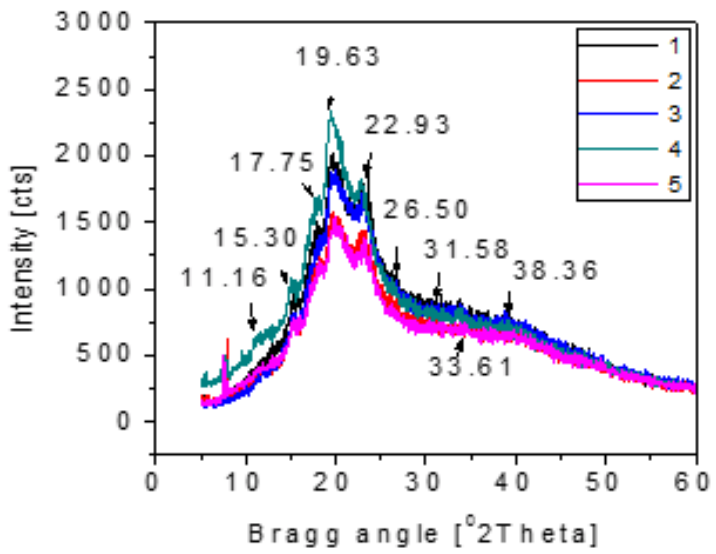

Fig. 1. Relationship between the XRD diffractograms shape and the particles size of sieved fractions used in achieving of each

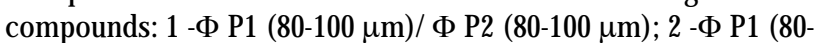
$100 \mu \mathrm{m}) / \phi$ P2 (100-200 $\mu \mathrm{m}) ; 3$ - $\Phi$ P1 (80-100 $\mu \mathrm{m}) /$ Ф P2 (200-300

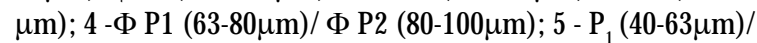
$P_{2}(80-100 \mu \mathrm{m})$

All the obtained diffractograms have the same wide diffraction angle, between $502 \theta$ and $50^{\circ} 2 \theta$, with maximum at almost the same diffraction angle of about $19^{\circ} 2 \theta$ as the main diffraction peak of PVOH [49]. This large diffraction angle presents small shoulders, at diffraction angles easily translated as those found either in starch or in PVOH $\left(23.57^{\circ} 2 \theta / 22.93^{\circ} 2 \theta / 15.1602 \theta\right.$ from starch and $40.72^{\circ} 2 \theta$ $/ 11.852 \theta$ from PVOH [49]).

These diffractograms have proved the advanced miscibility between starch and PVOH as it has been demonstrated already [14]. The novelty is related to the dependency of the compound miscibility on the particles size of the fractions compounded in each situation. The most convenient miscibility was obtained for the compound achieved from starch fraction with small particles particles of $63-80 \mu \mathrm{m}$ and those of PVOH sized as $80 \mu \mathrm{m}-100 \mu \mathrm{m}$ (fig. 1).

The SEM micrographs emphasized that the compounds achieved with sieved fractions containing large particles, enclosed many defects, sometimes visible to the naked eye (figs. 2-4). The greater the particles size of the compounded fractions was, the bigger the imperfections as voids, cracks and fractures of the resulted compounds were.

The number and the magnitude of the appeared defects were related with the dependency of the melting behavior on the particles size. At the same temperature, in the same time, some particles will melt, the smaller ones will degrade and will change the new compounds color and the larger ones will remain as unmelted insertions into the polymeric matrix, around which the defects (cracks, voids, fractures etc.) will appear. The new compounds always will contain, near unmelted particles because of their size, rests from the starch grains, represented by the clustered amylopectin macromolecules which cannot be intimately compounded with linear macromolecules of PVOH or amylose[28]. Otherwise these rests are very well visible on the SEM micrographs (figs. 2-4).

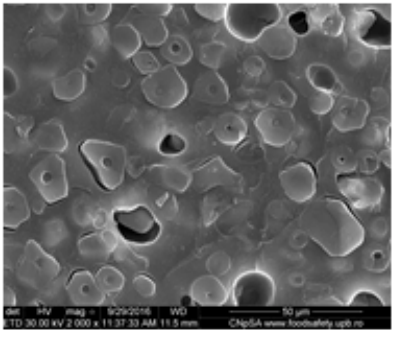

$2000 \mathrm{X}$

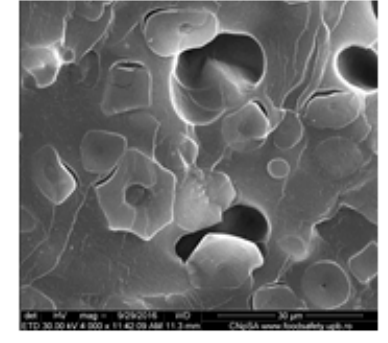

$4000 \mathrm{X}$
Fig. 2. Morphological defects of the compound obtained using starch with particles of $80-100 \mu \mathrm{m}$ and $\mathrm{PVOH}$ with particles of $100-200 \mu \mathrm{m}$ ( $1 / 1$ blending ratio)

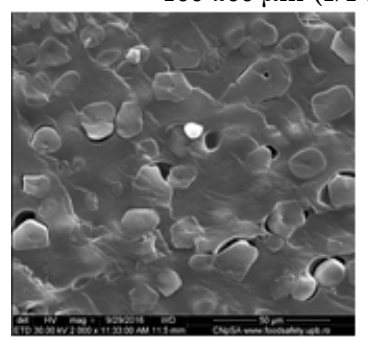

2000X

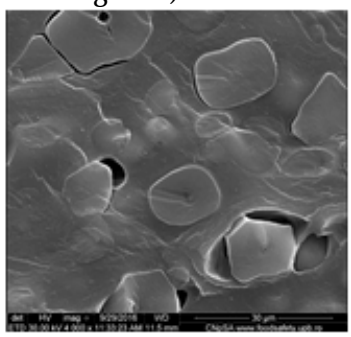

$4000 \mathrm{X}$
Fig. 3. Morphological defects of compound obtained from 80-100 $\mu \mathrm{m}$ sized starch with PVOH having particles of $200-300 \mu \mathrm{m}$ ( $1 / 1$ blending ratio)

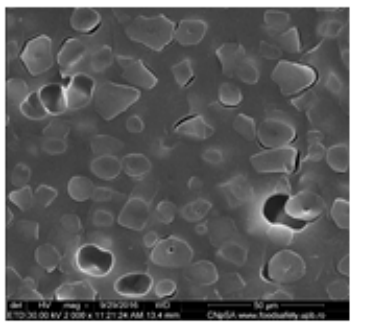

2000X

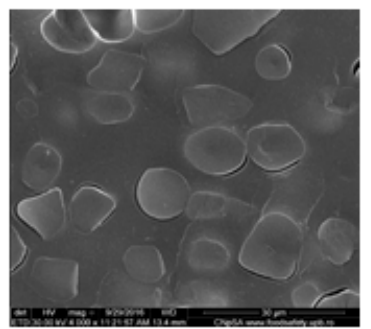

4000X
Fig. 4. Morphological defects of the compound achieved from starch with 40-63 $\mu \mathrm{m}$ sized particles and PVOH with particles of 80 - $100 \mu \mathrm{m}$ (1/1 blending ratio)

Since the sieving was not very narrow and each fraction still contains particles with differences in size of $20 \mu \mathrm{m}$, the coloring of the compounds was very much diminished, but not entirely eliminated.

The viscoelastic properties of the new compounds depend as well on the two polymers particles size (fig. 5). The studied compounds exhibited elastic behavior in a large temperature range, from $-80^{\circ} \mathrm{C}$ to $-60^{\circ} \mathrm{C}$, when, controlled by the particles size, the storage module ( $\left.E^{\prime}\right)$ had values from $2.3 * 103 \mathrm{MPa}$ to $6.4 * 103 \mathrm{MPa}$ (fig. $5 \mathrm{a}$ ). The smaller was the particles size of the two polymers which were compounded, the higher was the elastic deformation which was generated through compounding (e.g. blend obtained from starch of $80 \mu \mathrm{m}-63 \mu \mathrm{m}$; curve 5 , fig. 5 a).

In the same temperature limits from -80 to $-60^{\circ} \mathrm{C}$, regulated by the particles size, the energy loss due to the material morphological defects (viscous deformation), expressed by the loss modulus ( $\left.E^{\prime \prime}\right)$, varied between $2.1 * 102 \mathrm{MPa}$ and $1.2 * 103 \mathrm{MPa}$ (fig. 5b). The highest energy 
loss was recorded for the compound achieved using big PVOH particles of $300-200 \mu \mathrm{m}$ and starch sized as $80 \mu \mathrm{m}$ $-100 \mathrm{~mm}$.
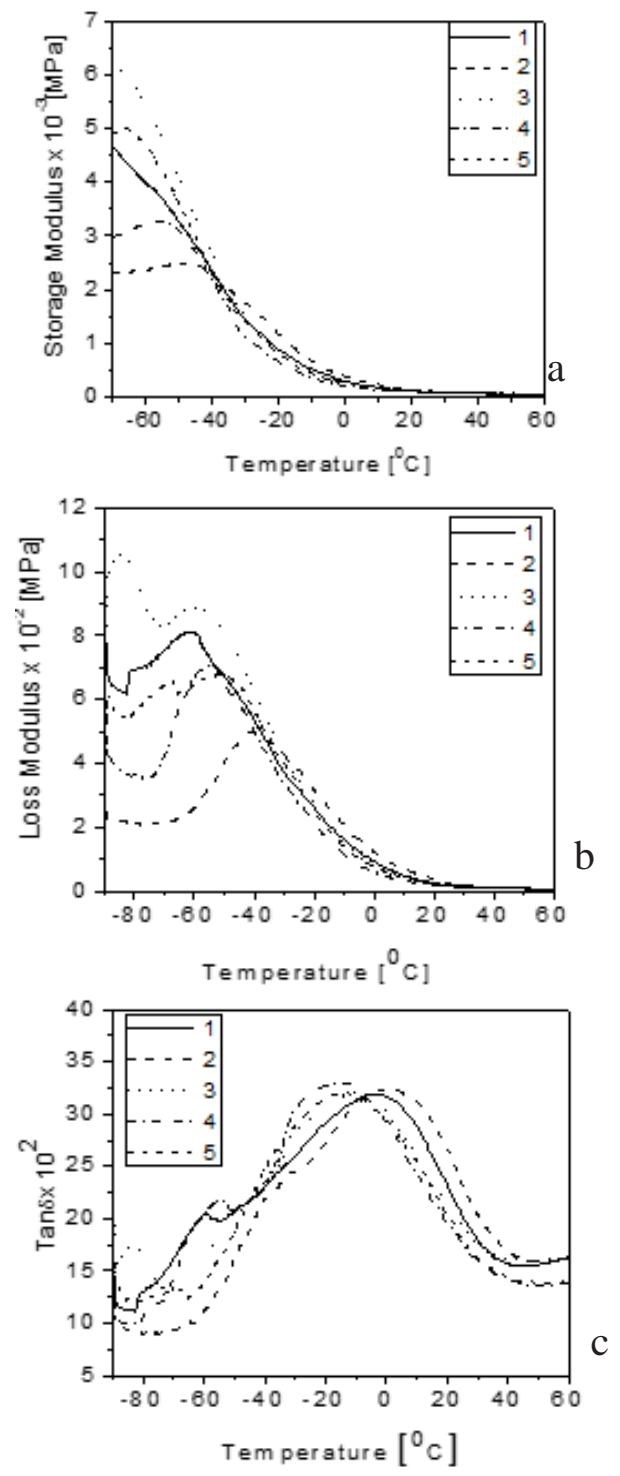

Fig. 5. The dependence of the storage modulus (a), loss modulus (b) and $\tan \delta$ (c) of new compounds on the temperature and the particle size of fractions used in obtaining of each of them ( $1-P_{1}$

$(80-100 \mu \mathrm{m}) / \mathrm{P}_{2}(80-100 \mu \mathrm{m}) ; 2-\mathrm{P}_{1}(80-100 \mu \mathrm{m}) / \mathrm{P}_{2}(100-200 \mu \mathrm{m})$;

$3-P_{1}(80-100 \mu \mathrm{m}) / P_{2}(200-300 \mu \mathrm{m}) ; 4-\mathrm{P}_{1}(63-80 \mu \mathrm{m}) / \mathrm{P}_{2}(80-100 \mu \mathrm{m})$; $\left.5-P_{1}(63-80 \mu m) / P_{2}(80-100 \mu m)\right)$

The dependence of $\tan \delta$ on the temperature indicated, as it was expected that, because of the high plasticizing degree, these compounds exhibit a wide glass transition, mainly in the negative temperature range. Depending on the particles size compounded in each situations, this transition has the onset temperature from -70 to $-55^{\circ} \mathrm{C}$, the maximum temperature between -20 and $7^{\circ} \mathrm{C}$ and end temperature from 30 to $45^{\circ} \mathrm{C}$ (fig. $5 \mathrm{C}$ ). Controlled by the particles size, the glass transition presents, greater or smaller shoulders which indicate enhanced or reduced miscibility. The diffractograms of the compounds achieved from fractions with large particles had some shoulders between 45 and $-75^{\circ} \mathrm{C}$ which means lower miscibility. The compound obtained from starch with particles of $40 \mu \mathrm{m}$ $63 \mu \mathrm{m}$ and PVOH containing particles ranged as 100-80 $\mu \mathrm{m}$ had a glass transition without shoulders meaning misciblility at thermodynamical level, even the starch content was $50 \%$. Taking into account that miscibility at this level is a guaranty of compound stability unlimited period of time, it can be concluded that the polymeric particles, through their size, control even the life time of the resulted compound.

The DMA and SEM results are in good agreement. They reveal that the starch -PVOH compounds obtained from small sized particles are almost total miscible, presenting a single glass transition without shoulders, entirely different as those of individual components and almost a continuous phase with few defects as voids etc. If the two polymers would had as result of the obtaining procedure particles of comparable size than the obtaining of less defects and compact morphology starch-based compounds would be much easier.

\section{Controlling the process sensitivity \\ Stabilization-plasticization}

The polymer degradation at melt processing can be controlled byscavenging the newly appeared radicals [50]. The plasticizers are used in polymers formulation to make them more flexible as result of decreasing the physical attractions between the macromolecules making, in this way the macromolecules less susceptible atcompounding degradation [50,51]. In this respects, starch-PVOH compounds, with different blending ratios and selected plasticizing and stabilization content have been analyzed (table 1, 2).

Table 1

THE COLOR OF THE 60 / 40 (STARCH /PVOH) COMPOUND, THE

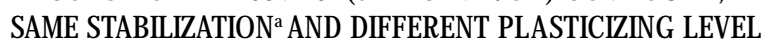

\begin{tabular}{|c|c|c|c|}
\hline Plasticizer, $\%$ & Stabilizer, $\%$ & Visual color & Yellow index \\
\hline 20 & 0.5 & light brown & 40 \\
\hline 30 & 0.5 & brown & 39 \\
\hline 60 & 0.5 & yellow & 40 \\
\hline
\end{tabular}

${ }^{a} 0.5 \%$ antioxidant Irganox B215; ${ }^{b}$ reported at $100 \%$ blend of starch with PVOH (60/40 blending ratio)

However, regardless the antioxidants and plasticizers content, the results were not what was expected, mainly because all the compounds were, more or less, still colored. The color of the unstabilized compounds or of those with small amount of antioxidant $(0.1 \%)$ was almost the same (tables 1, 2).

Furthermore, the additional stabilization did not eliminate the coloring (table 2). It seems that, for the starch -PVOH compounds, the appearance of radicals because of degradation cannot be stopped via stabilizationplasticization.

\begin{tabular}{|c|c|c|c|}
\hline $\begin{array}{c}\text { Starch-PVOH blending } \\
\text { ratio Plasticizer, } \%\end{array}$ & Stabilizer ${ }^{2}, \%$ & Visual color & Yellow index \\
\hline $70 / 30 / 60$ & 5 & white & 19 \\
\hline $70 / 30 / 40$ & 5 & white & 20 \\
\hline $70 / 30 / 40$ & 5 & white & 22 \\
\hline $70 / 30 / 40$ & 2.5 & white- yellowish & 21 \\
\hline $70 / 30 / 50$ & 0.5 & yellow & 33 \\
\hline $60 / 40 / 40$ & - & light brown & 32 \\
\hline $60 / 40 / 40$ & 0.5 & dark brown & 38 \\
\hline
\end{tabular}

${ }^{\mathrm{a}}$ reported at $100 \%$ blend of starch with PVOH; ${ }^{b} 0.5 \%$ Irganox B2 15 
Table 3

THE DEPENDENCE OF TENSILE PROPERTIES AND COLOR OF STARCH - PVOH COMPOUNDS ON THE STARCH CONTENT AND COMPOUNDING TEMPERATURE

\begin{tabular}{|c|c|c|c|c|c|c|}
\hline $\begin{array}{c}\text { Starch, } \\
\%\end{array}$ & T Brebender, ${ }^{\circ} \mathrm{C}$ & T roller, ${ }^{\circ} \mathrm{C}$ & $\begin{array}{c}\text { Tensile strength at break, } \\
\mathrm{MPa}\end{array}$ & $\begin{array}{c}\text { Elongation at } \\
\text { break, } \%\end{array}$ & Visual color & Yellow index \\
\hline \multirow{2}{*}{10} & 140 & 140 & $6-7$ & $350-400$ & yellow & 29 \\
\cline { 2 - 7 } & 170 & 140 & $7-8$ & 350 & brown & 38 \\
\hline \multirow{2}{*}{20} & 140 & 140 & $5.8-7$ & $350-400$ & yellow & 27 \\
\cline { 2 - 7 } & 170 & 140 & $6-7$ & $320-348$ & yellow-brown & 35 \\
\hline \multirow{2}{*}{30} & 140 & 140 & $5.5-7$ & $300-400$ & yellow-cream & 26 \\
\cline { 2 - 7 } & 170 & 140 & $4.5-6$ & $300-350$ & brown & 36 \\
\hline \multirow{2}{*}{40} & 140 & 140 & 5 & $50-380$ & yellow & 24 \\
\cline { 2 - 7 } & 170 & 140 & $4.5-5$ & & & 28 \\
\hline
\end{tabular}

Finding the windows of melt processing conditions

Some compounds with less than $50 \%$ starch were injected at two different temperatures, respectively at 140 and $170^{\circ} \mathrm{C}$. At $140^{\circ} \mathrm{C}$, the tensile properties and color depend on the starch content od each compound. The smaller the starch content were, the greater the tensile properties and the smaller the color changing were (table 3 ).

On the other side, at $170^{\circ} \mathrm{C}$, the increasing of the tensile strength, the decreasing of elongation at break and the coloring of all compounds can be explained only through PVOH crosslinking because its thermo-oxidative degradation. The degradation was stronger as the starch content of the compound was smaller (table 3 ).

If, at $145^{\circ} \mathrm{C}$, the specimens achieved from compound with $50 \%$ starch were incomplete, yellow and contained voids, at smaller temperature of $90^{\circ} \mathrm{C}$ they enclosed unmelted material. The specimens obtained from the blend with $70 \%$ starch incorporated also, between $90^{\circ} \mathrm{C}$ and $120^{\circ} \mathrm{C}$, unmelted material. The specimens were yellow brown and had discontinuous surfaces when the injection temperatures was between 150 and $170^{\circ} \mathrm{C}$. The melt was very sticky and the specimens were hardly removed from the mold if the injection temperature was $170^{\circ} \mathrm{C}$. If the injection was made at $180^{\circ} \mathrm{C}$, the melt had smallest viscosity and flowed together with a lot of degradation gases which did impossible the filling of the molds and the obtaining of complete specimens. It has been observed that the temperature range in which fewer defects and smaller color change depend on the content of each starch compound and was of $110^{\circ} \mathrm{C}-120^{\circ} \mathrm{C}$ for the compound with $10-50 \%$ starch and by $125^{\circ} \mathrm{C}-135^{\circ} \mathrm{C}$ for those with 60 $-90 \%$ starch.

Consequently, the process sensitive materials like compounds based on starch and $\mathrm{PVOH}$ require the finding of the windows of the obtaining conditions for two main compositional groups, one with starch as minor and the other as major component. The slightly yellow shades of the specimens injected even under selected conditions showed that the problem of the color change at melt compounding is not solved yet, probably because the formulation still needs to be improved.

\section{Diminishing the melt internal friction}

If the compounds did not contained flow agent, then, regardless the starch content and the extrusion conditions, the SR (is defined as ratio between the melt flow rate through a capillary and its gap [52-54] and controls the degree of homogenization) had low values ranged as 1.2 $\mathrm{s}^{-1}-25 \mathrm{~s}^{-1}$, (fig. 6 a). In case of formulation with flow agent (fig. $6 \mathrm{~b}$ ), the SR reached values as $25 \mathrm{~s}^{1}-70 \mathrm{~s}^{-1}$, mainly at 5 $\mathrm{kg}-10 \mathrm{~kg}$ indexer load.

At high indexer load, the dependence of the SR on the starch content was much obvious.

In the absence of the flow agent, the fluidity of the compounds, expressed by the MFI values, was dependent on the indexers load and was ranged from 1 to $15 \mathrm{~g} / 10$
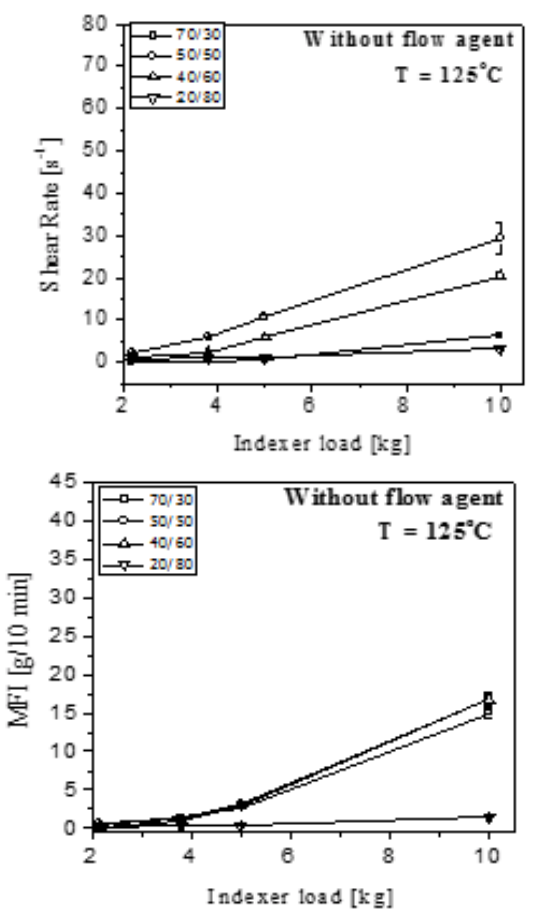

(a)
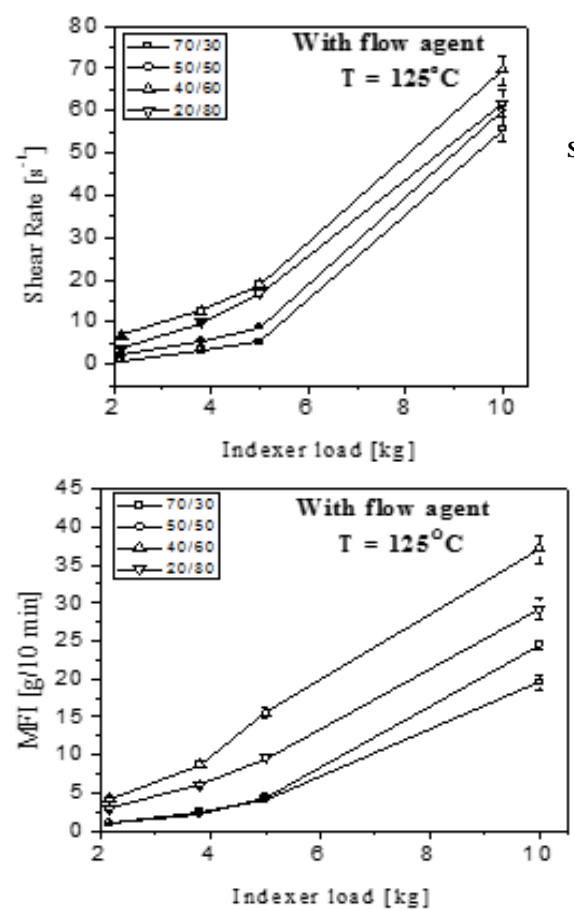

(b)
Fig. 6. Dependency of the shear rate of the starch -PVOH compounds on the starch content, the melt flow conditions and the formulation without (a) or with (b) flow agent

Fig. 7. Dependency of the fluidity of the starch - PVOH compounds on the starch content, the melt flow conditions and the formulation without (a) or with (b) flow agent 
min. (fig. 7 a). In case of the compound with $20 \%$ starch without flow agent, no variation of the fluidity with indexer loading has been observed, probably because it needs to flow well a higher temperature than $125^{\circ} \mathrm{C}$. If the formulation was made with flow agent, then the fluidity increased according to the indexer load and the starch content (fig. 7 b). At $10 \mathrm{~kg}$, the fluidity is almost twice greater as for the compound without flow agent.

The flow agent decreased to half the dynamic viscosity of the studied compounds melt $(\eta)$ (internal friction resulted in a melt when a fluid layer moves in relation to another, namely the melt's resistance to flow -Newton's friction law [46, 52, 55, 56]) (fig. 8).

The melt resistance to flow of the compounds with flow agent and more than $50 \%$ starch, was mainly at low load (of $2.19 \mathrm{~kg}$ and $3.18 \mathrm{~kg}$ ), 2-3 times greater than those of the compounds with less than $50 \%$ starch. The explanation is related to the high content of clustered branched amylopectin in case of the compounds with more than 50 $\%$ starch. Amylopectin flows more heavily than the linear macromolecules of amylose or PVOH. The flow temperature of $125^{\circ} \mathrm{C}$ is optimal for all the studied compounds with the exception of those with $20 \%$ starch, which probably, because of high content of PVOH, flow well at higher temperature.

Obviously, small values of melt resistance to flow are helpful firstly, to ensure good flow during compounding and $3 \mathrm{D}$ printing. Secondly, low melt resistance to flow is equivalent with low mechanical stress acting on the melted macromolecules and thus a small probability of new radicals appearances at melt processing.

The formulation with flow agent diminished by almost 6 times the activation energy $\left(E_{a}\right)$ of the melt viscous flow for all the studied compositions (table 4).

A smaller Ea is equivalent with low energy needed at melt compounding, latter at shaping as filament of the obtained compounds and then during 3D printing. The melt density is higher for all the compounds with flow agent (table 5) because by increasing the macromolecules capacity to move by flow, the resulted packaging degree will be higher as in its absence. For this reason the melt density will be higher and the new products will contain smaller defects as voids or cavities.

The diminishing of the melt density for the compounds with less than $50 \%$ starch formulated with flow agent and their good flowability under high load of $5 \mathrm{~kg}$ and $10 \mathrm{~kg}$ when need the smallest activation energy to flow (table 5), is understandable. It is more easier to pack a melted linear polymer such amylose or/and PVOH than a branched one like amylopectin which represents almost $70 \%$ from the used corn starch.

It can be concluded that the flow agent acts as a good improver of the flowability for the melt of all the studied starch - PVOH compositions because control properties as fluidity, resistence to flow, activation energy of the viscous flow and the melt density .

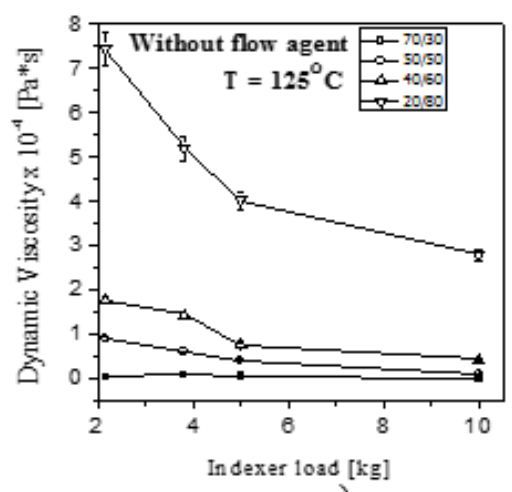

a)

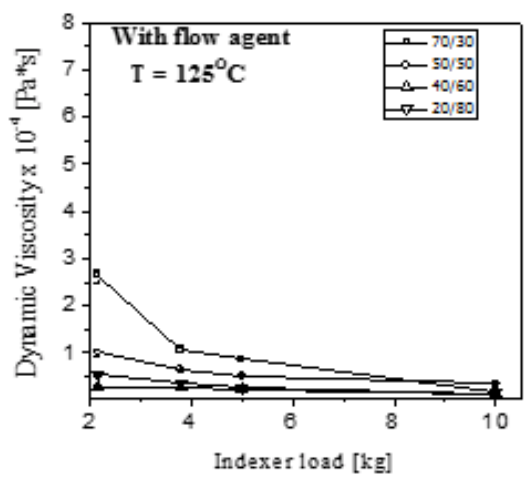

(b)
Fig. 8. Dependency of the melt flow resistance of the starch - PVOH compounds on the starch content, the melt flow conditions and the formulation without (a) or with (b) flow agent

Table 4

DEPENDENCY OF THE ACTIVATION ENERGY OF THE VISCOUS FLOW OF THE STUDIED COMPOUNDS ON THE STARCH CONTENT, FLOW CONDITIONS AND THE FORMULATION WITHOUT OR WITH FLOW AGENT

\begin{tabular}{|c|c|c|c|c|c|c|c|c|}
\hline \multirow{3}{*}{$\begin{array}{c}\text { Starch content of } \\
\text { the blend, \% }\end{array}$} & \multicolumn{9}{|c|}{ Without flow agent } & \multicolumn{5}{c|}{ With flowing agent } \\
\cline { 2 - 9 } & \multicolumn{3}{|c|}{ Indexer load, kg } & \multicolumn{4}{c|}{ Indexer load, kg } \\
\cline { 2 - 9 } & 2.16 & 3.8 & 5 & 10 & 2.16 & 3.8 & 5 & 10 \\
\hline 70 & 97.31 & 111.61 & 92.02 & 96.01 & 18.64 & 30.52 & 34.17 & 28.57 \\
\hline 50 & 249.26 & 278.14 & 235.17 & 208.85 & 170.29 & 215.07 & 190.17 & 185.43 \\
\hline 40 & 243.75 & 201.09 & 127.23 & 123.81 & 67.06 & 106.58 & 56.37 & 114.30 \\
\hline 20 & 272.47 & 299.04 & 336.54 & 381.26 & 154.57 & 155.69 & 135.87 & 134.46 \\
\hline
\end{tabular}

Table 5

DEPENDENCY OF THE MELT DENSITY OF THE STARCH - PVOH COMPOUNDS ON THE STARCH CONTENT AND THE FORMULATION WITHOUT OR WITH FLOW AGENT

\begin{tabular}{|l|c|c|c|c|c|c|c|c|}
\hline \multirow{3}{*}{$\begin{array}{c}\text { Starch content of } \\
\text { the blend, } \%\end{array}$} & \multicolumn{9}{|c|}{ Melt density, $\mathrm{g} / \mathrm{cm}^{3}$} \\
\cline { 2 - 9 } & \multicolumn{3}{|c|}{ Without flow agent } & \multicolumn{5}{c|}{ With flow agent } \\
\cline { 2 - 9 } & \multicolumn{3}{|c|}{ Indexer load, kg } & \multicolumn{5}{c|}{ Indexer load, kg } \\
\cline { 2 - 9 } & 2.16 & 3.8 & 5 & 10 & 2.16 & 3.8 & 5 & 10 \\
\hline 70 & 0.097 & 0.166 & 0.213 & 0.616 & 0.244 & 0.641 & 0.786 & 1.132 \\
\hline 50 & 0.082 & 0.173 & 0.279 & 1.071 & 0.559 & 0.986 & 1.228 & 1.338 \\
\hline 40 & 0.101 & 0.133 & 0.164 & 0.528 & 1.296 & 1.281 & 1.205 & 1.155 \\
\hline 20 & 0.096 & 0.139 & 0.176 & 0.634 & 1.198 & 1.180 & 1.133 & 1.115 \\
\hline
\end{tabular}



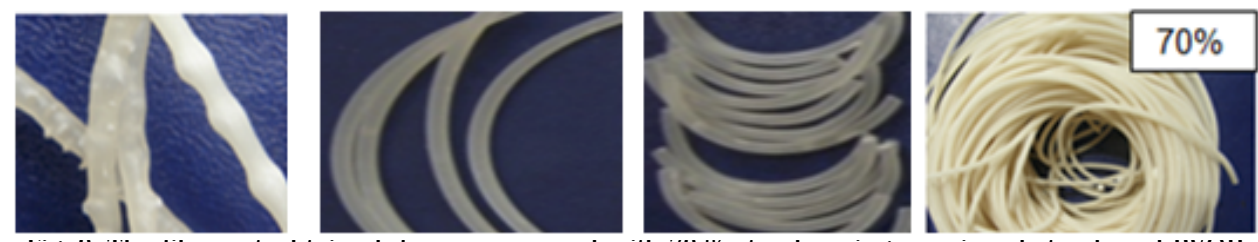

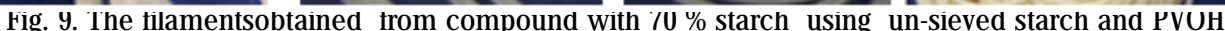
without controlling the process sensitivity (a) or sieved starch and PVOH and controlled process sensitivity (b, c, d) (a - Many defects as voids; b, c, d - Without defects and natural colour)

The main effect of the improving of the melt flowability of the starch-PVOH compounds with the help of the flow agent was the achieving, white, undegraded compounds. The double bonds responsible for the coloring of the starchbased compounds [14] had no conditions to develop, as the radicals no longer appear.

As it was demonstrated [57-59], during extrusion of starch, significant shear degradation happened in amylopectin component of starch, while high amylose starch could resist to the chain scission. Amylopectin with high branching density and short branch length is of higher susceptibility to shear degradation due to its inflexible structure $[58,59]$. Considering also the high content of amylopectin of the used starch (70\%) itcan be appreciated that the observed degradation during melt compounding, were generated, both by the degradation of the amylopectin from starch and of the PVOH .

As compared with the known solution of scavenge of the radicals from the melted polymeric compounds through stabilization, which can be ineffective for process sensitiv starch-based compounds, the prevention of the radicals formation through diminishing the melt resistance to flow is much safer. Otherwise, as it has been shown, this is the only solution to make non-stained, white starch basedcompounds.

Shaping of selected compounds into 3D printing filaments

To test the extrudability and to analyze the surface roughness of the new filaments, selected compounds with various starch contents (20-90\%) were first shaped as bands with $1 \mathrm{~mm}$ thickness and $10 \mathrm{~mm}$ width. It was observed that if the roughness of these bands was of $+/$ $0.04 \mathrm{~mm}$, the corresponding filaments had silky and smooth surface, suitable diameter tolerance $(+/-0.047$ $\mathrm{mm}$ ) and ovality and have proven good behavior at 3D printing (fig. 9).

\section{Conclusions}

It was found, that the turning of corn starch via melt modification with PVOH, into thermoplastic compounds for high quality $3 \mathrm{D}$ printing filaments can be engineered by providing similar melting behavior of the starch and $\mathrm{PVOH}$ powder and by controlling the process sensitivity of the new compounds.

Defects like voids, cracks, etc. appear around both the un-melted polymer particles due to their too much large size and/or in proximate of the residues of the amylopectin from the starch grains which, because of its clustered structure, cannot be intimately compounded with the linear macromolecules of amylose and/or those of $\mathrm{PVOH}$. The more the unmelted polymeric particles because of their size and/or the amylopectin content are, the greater the overall defects of the final compounds will be. By compounding the two polymers as powder, with similar small sized particles it was controlled even the miscibility of the two polymers and so, by using starch with $70 \%$ amylopectin, a miscible compound having a single glass transition have been obtained.
The controlling of the process sensitivity of the starch based-compounds proved to be a better solution to obtain natural colour filaments and was mainly achieved by diminishing the meltresistance to flow via formulation with a flow agent.

The filaments obtained from the selected starch basedcompounds obtained using starch and PVOH with similar sized particles and controlling the process sensitivity at melt compounding had silky, smooth surface, diameter tolerance of $+/-0.04 \mathrm{~mm}$, ovality of $(0.005 \mathrm{~mm}-0.06 \mathrm{~mm})$ and had a good behavior at 3D printing.

Acknowledgements: This work was supported by the Romanian Ministry of Research and Innovation, CCCDI - UEFISCDI through projects number No. 59, No. 32101, No. 34N, No. 40/5. The authors are grateful to their colleagues who were partially involved in experiments and manuscript preparation.

\section{References}

1. REDWOOD B., SCHOFFER F., GARRET B.: The 3D Printing Handbook: Technologies, design and applications, ISBN 978-90-8274850-5, 3D HUBS 2017.

2.*** EN ISO/ASTM 52900: Additive manufacturing. General principles. Terminology 2017.

3. KUZNETSOV V. E., SOLONIN A. N., URZHUMTSEV O. D., SCHILLING R., TAVITOV A. G.: Strength of PLA Components Fabricated with Fused Deposition Technology Using a Desktop 3D Printer as a Function of Geometrical Parameters of the Process. Polymers, 10, 2018, p. 1-11. DOI:10.3390/polym10030313.

4. TYMRAK B. M., KREIGER M., PEARCE J. M.: Mechanical properties of components fabricated with open-source 3-D printers under realistic environmental conditions. Materials and Design, 58, 2014, p. 242-246. 5. OTHMAN N., AZAHARI N. A., ISMAIL H.: Thermal properties of polyvinyl alcohol (PVOH)/corn starch blend film. Malaysian Polymer Journal, 2011, p. 147-154.

6.NGUYEN VU H. P., LUMDUBWONG N.: Starch behaviors and mechanical properties of starch blend films with different plasticizers. Carbohydrate Polymers, 154, 2016, p. 112-120.

7.MITTAL V.: Nanocomposites with biodegradable polymers: synthesis, properties, and future perspectives. Publisher Oxford University Press, 2011.

DOI:10.1093/acprof:0so/9780199581924.001.0001.

8. SINHA-RAY S. S.: Environmentally friendly polymer matrices for composites. In 'Environmentally Friendly Polymer Nanocomposites: Types, Processing and Properties'. Woodhead Publishing Lt., 2013, p. 25-40.

9. ZIA UD D., XIONG H. G., FEl P.: Physical and chemical modification ofcompounds: A review. Food and Nutrition Sciences, 57, 2017, p. 2691-2705.

10. TANG X. Z., ALAVI S.: Recent advances in starch, polyvinyl alcohol based polymer compounds, nanocomposites and their biodegradability. Carbohydrate Polymers, 85, 2011, p. 7-16.

11. ZANELA J., CASAGRANDE M., SHIRAI M. A., APARECIDO DE LIMA V., YANASHITA F.: Biodegradable compounds of starch/polyvinyl alcohol/glycerol: multivariate analysis of the mechanical properties. Polimeros, 26, 2016, p. 193-196.

12. SIN L.T., RAHMAN W.A.W.A., RAHMAT A. R., MOKHTAR M.: Determination of thermal stability and activation energy of polyvinyl 
alcohol-cassava starch compounds. Carbohydrate Polymers, 83, 2011, p. 303-305

13. DIMONIE D., MUSAT M., DONCEA S. M., DAMIAN C., ANTON L., VASILE E., TRUSCA R., RAPA M.: Controlling the melt resistance to flow as a possibility of improving the miscibility and the time behavior of some compounds based on starch. International J ournal of Polymer Science, Volume 2015, Article ID 582901, 12, 2015. DOI: 10.1155/2015/ 582901.

14. DIMONIE D., PETRACHE M., DAMIAN C., ANTON L., MUSAT M., DIMA S. O., JINESCU C., RAPA M.: New Evidences on the Process Sensitivity of Some Renewable Compounds Based on Starch considering Their Melt Rheological Properties. International J ournal of Polymer Science, Volume 2016, Article ID 7873120, 10 2016.DOI: $10.1155 / 2016 / 7873120$

15. AYDIN A. A., ILBERG V.: Effect of different polyol-based plasticizers on thermal properties of polyvinyl alcohol: starch compounds. Carbohydrate Polymers, 136, 2016, p. 441-448.

16. ISMAIL H., ZAABA N. F.: Effect of additives on properties of polyvinyl alcohol (PVA)/tapioca starch biodegradable films. Polymer - Plastics Technology and Engineering, 50, 2011, p. 1214-1219.

17. ASIF JAVED, HENRIK ULLSTEN, HENRIK ULLSTEN MARIE, ERNSTSSON MARIE, ERNSTSSON LARS, JARNSTROM LARS JARNSTROM, Study of starch and starch-PVOH compounds and effects of plasticizers on mechanical and barrier properties of coated paperboard, Nordic Pulp and Paper Research J ournal 31(03):499-510, September 2016, DOI: 10.3183/NPPRJ -2016-31-03-p499-510.

18. GONZALEZ-FORTE L., PARDINI O., AMALVI J .: Starch/Polyvinyl Alcohol Compounds Containing Polyurethane as Plasticizer. Journal of Composites and Biodegradable Polymers, 4, 2016, p. 2-10.

19. WESTHOFF R. P., KWOLEK W. F., OTEY F. H.: Starch - poly-vinyl alcohol films - effect on various plasticizers. Starke, 31, 1979, p. 163165.

20. SINGHA A. S., KAPOO H.: Effects of plasticizer/cross-linker on the mechanical and thermal properties of starch/PVA compounds. Iranian Polymer Journal, 23, 2014, p. 655-662.

21. YOON S. D., CHOUGH S. H., PARK, H. R.: Preparation of resistant starch/poly(vinyl alcohol) blend films with added plasticizer and crosslinking agents. J ournal of Applied Polymer Science, 106, 2007, p. 2485-2493.

22. B. SREEDHAR, D. K. CHATTOPADHYAY, M. SRI HARI KARUNAKAR, A. R. K. SASTRY, Thermal and Surface Characterization of Plasticized Starch Polyvinyl Alcohol Compounds Crosslinked with Epichlorohydrin, Journal of Applied Polymer Science, Vol. 101, 2006, p. 25-34, Wiley Periodicals, Inc.

23. SATHYA KALAMBUR AND SYED S. H. RIZVI, An overview of starchbased plastic compounds from reactive extrusion, JOURNAL OF PLASTIC FILM \& SHEETING, VOL. 22-J ANUARY 2006 398756-0879/06/01 0039-20 \$10.00/0DOI: 10.1177/8756087906062729

24. FRONE A. N., NICOLAE C. A., GABOR R. A., PANAITESCU D. M.: Thermal properties of water-resistant starch - polyvinyl alcohol films modified with cellulose nanofibers. Polymer Degradation and Stability, 121, 2015, p. 385-397.

25. ALI S. S.: Fundamental interactions and physical properties of starch,poly vinyl alcohol and montmorillonite clay based nanocomposites prepared using solution mixing and melt extrusion. Kansas State University 2010.

26. WANG W., ZHANG H., JIA R., DAI Y., DONG H., HOU H., GUO Q.: High performance extrusion blown starch/polyvinyl alcohol/clay nanocomposite films. Food Hydrocolloids, 79, 2018, p. 534-543.

27. ZOU G. X., PING-QU J., LIANG-ZOU X.: Extruded Starch/PVA Composites: Water resistance, thermal properties, and morphology. J ournal of Elastomers and Plastics, 40, 2008, p. 303-316.

28. DIMONIE D., SOCOTEANU R., DONCEA S., POP F., PETRE C., DUMITRIU I., FIERASCU R.: Miscibility estimation of some compounds based on starch. e-Polymers, 11, 2011, p. 957-970.

29. LIU H. S., YU L., XIE F., CHEN L.: Gelatinizationof corn starch with different amylose/amylopectin content. Carbohydrate Polymers, 65 , 2006, p. 357-363.
30. LIU H., YU L., TONG Z., CHEN L.: Retrogradation of waxy cornstarch studied by DSC. Starch-Starke., 62, 2010, p. 524-529.

31. LIU H. S., YU L., CHEN L., LI L.: Retrogradation of corn starch after thermal treatment at different temperatures. Carbohydrate Polymers, 69, 2007, p. 756-762.

32. LIU P., YU H. L., LIU L. H., CHEN LI L.: Glass transition temperature of starch studied by a high-speed DSC. Carbohydrate Polymers, 77, 2009, p. 250-253.

33. LIU P., YU L., WANG X., LI D., CHEN L., LI X.: Glass transition temperature ofcompounds with different amylose/amylopectin ratios. Journal of Cereal Science, 51, 2010, p. 388-391.

34. GRIGORESCU R. M., DIMONIE D., DIMONIE M., HUBCA G.: Some aspects concerning the rheology of biodegradable starch based materials. Scientific bulletin, Series B: Chemistry and materials Science (UPB), 74, 2012, p. 37-48.

35. ZHIJUN WU, JING] ING W, TINGTING PENG , YUTONG LI , DERONG LIN , BAOSHAN XING, CHUNXIAO LI, YUQIU YANG, LI YANG, LIHUA ZHANG, RONGCHAO MA, WEIXIONG WU, XIAORONG LV, JIANWU DAI AND GUOQUAN HAN, Preparation and Application of Starch/Polyvinyl Alcohol/Citric Acid Ternary Blend Antimicrobial Functional Food Packaging Films, Polymers 2017, 9, p. 102; doi:10.3390/polym9030102 36. HELENA N. CHIA AND BENJ AMIN M. WU, Recent advances in 3D printing of biomaterials, Journal of Biological Engineering 2015, 9, p. 4, https://doi.org/10.1186/s13036-015-0001-4

37. BIN-DAHMAN O. A., JOSE J., AL-HARTHI M. A.: Effect of natural weather aging on the properties of poly(vinyl alcohol)/starch/graphene nanocomposite. Starch-Starke., 69, 7-8, 2017.

38. TIAN H. F., YAN J., RAJULU A. V., XIANG A., LUO X. G.: Fabrication and properties of polyvinyl alcohol/starch blend films: Effect of composition and humidity. International Journal of Biological Macromolecules, 96, 2017, p. 518-523.

39. CHEN Y., CAO X., CHANG P. R., HUNEAULT M. A.: Comparative study on the films of poly(vinyl alcohol)/pea starch nanocrystals and poly(vinyl alcohol)/native pea starch. Carbohydrate Polymers, 73, 2008, p. 8-17.

40. SADHU S. D., SONI A., VARMANI S. G., GARG M.: Preparation of starch-poly vinyl alcohol (PVA) blend usingpotato and study of its mechanical properties. International J ournal of Pharmaceutical Science Invention, 3, 2014, p. 33-37.

41. CAPONE C., DILANDRO L., INZOLI F., PENCO M., SARTORE L.: Thermal and mechanical degradation during polymer extrusion processing. Polymer Engineering and Science, 47, 2007, p. 1813-1819. 42. BILLINGHAM N. C.: Degradation and Sstabilization of polymers. Materials Science and Technology, 2013, p. 470-506.

43. KIRSCHWENG B., TATRAALJAI D., FOLDES E., PUKANSZKY B.: Natural antioxidants as stabilizers for polymers. Polymer Degradation and Stability, 145, 2017, p. 25-40.

44. GACHTER R., MULLER H.: Plastics Additives handbook. Hanser Publisher 1987.

45. DIMONIE D., DIMONIE M., VASILIEVICI G.: Polyolefines mechanical recycling considering the carbonyl variation during the first life. Mat. Plast., 44, 2007, p. 361-364.

46. DIMONIE D., ZAHARIA C., ZECHERU T., PANAITESCU D., VASILE I.: Usage properties of some PVC-TPU compounds realized by physical modification. Mat. Plast., 43, 2006, p. 230-235.

47. STAICU D., PAVEN H.: The recovery of photodegraded low density polyethylene from green houses and solars (S-LD-PE). III. Rheological properties of the melts of certain compounds based on S-LD-PE. Polymer Degradation and Stability, 45, 1994, p. 71-76.

48. DIMONIE D., PETRE D., VASILIEVICI G.: Polyvinyl alcohol melt processing. J ournal of Elastomers and Plastics, 39, 2007, p. 181-194. 49. DIMONIE D., MUSAT M., DONCEA S. M., DAMINA C. M., ANTON L., VASILE E., TRUSCA R., RAPA M., Controlling the melt resistance to flow as possibility of improving the miscibility and the time behavior of some compounds basaed on starch", International Journal of Polymer Science, Volume 2015, article ID 582901, 12 pages, dx.doi.org/ $10.1155 / 2015 / 582901$. 
50. ZHANG Y. C., REMPEL C., LIU Q.: Thermoplastic Starch Processing and Characteristics-A Review. Food and Nutrition Sciences, 54, 2014, p. 1353-1370.

51. MEKONNEN T., MUSSONE P., KHALIL H., BRESSLER D.: Progress in bio-based plastics and plasticizing modifications. Journal of Materials Chemistry, 1, 2013, p. 13379-13398.

52. PRENTICE P.: Rheology and its role in plastics processing. Smithers Rapra Publishing 1995.

53. HADDOUT A., VILLOUTREIX G.: Polymer melt rheology at high shear rates. International Polymer Processing, 15, 2000, p. 291-296.

54. Understanding the Rheologyical Characteristics of Thermoplastic Polymers. TA instuments, http://www.tainstruments.com/pdf/ literature/AAN013 V 1 U Thermoplast.pdf, accessed at 25.06.2018. 55. SPERLING L. H.: Introduction to Physical Polymer Science Multicomponent Polymeric Materials. Wiley Blackwell (John Wiley \& Sons) 2005.
56. CHARLESL.ROHN, Analytical Polymer Rheology, Hanser Publishers, Munich Vienna New York, ISBN 1-56990-149-X, 1995

57. JIM W.GOODWIN, ROY W.HUGHES, Rheology for Chemists, Royal Society of Chemistry, ISBN 0-85404-616-X, 2000

58. LIU X. X., WANG Y. F., YU L., TONG Z., CHEN L., LIU H. S., LI X. X.: Thermal degradation and stability of starch under different processing conditions. Starch-Starke, 65, 2013, p. 48-60.

59. LIU W.C., HALLEY P. J., GILBERT R. G.: Mechanism of degradation of starch, a highly branched polymer, during extrusion. Macromolecules, 43, 2010, p. 2855-2864.

60. PENG Z., KONG L. X.: A thermal degradation mechanism of polyvinyl alcohol/silica nanocomposites. Polymer Degradation and Stability, 92, 2007, p. 1061-1071.

61.TAGHIZADEH M. T., SABOURI N.: Thermal degradation behavior of polyvinylalcohol/starch/carboxymethyl cellulose/clay nanocomposites. Universal J ournal of Chemistry, 2013, p. 21-29.

Manuscript received: 6.03 .2019 